\title{
Socio-Demographic Risk Factors Associated with Breast Cancer in Gaza Strip
}

\author{
Khalid Jamal Khadoura \\ College of Nursing, Islamic University of Gaza, Gaza Strip, Palestine
}

"Corresponding author: Khalid Jamal Khadoura, College of Nursing, Islamic University of Gaza, Gaza Strip, Palestine. Tel: +970599189117; E-Mail: K.khadourah@gmail.com

Citation: Khadoura KJ (2017) Socio-Demographic Risk Factors Associated with Breast Cancer in Gaza Strip. J NursWomens Health: JNWH-118. DOI:10.29011/JNWH-118. 100018

Received Date: 08 April 2017; Accepted Date: 16 May 2017; Published Date: 27 May 2017

\begin{abstract}
Background: Breast cancer is a critical disease in the global burden of disease; In Gaza Strip, breast cancer is considered a major public health problem. As expected by WHO, it is the first common cancer concerning females and the second leading cause of female death after cardiovascular disease. This study aimed to evaluate the effects ofsocio-demographic risk factors associated with breast cancer among breast cancer women in Gaza Strip.

Methodology: The study designed to be observational analytical retrospective investigation, hospital based case-control study, which consist of the name of Governorate, kinds of living area, marital status, number of children, educational level and housing type. The study population consisted of two types; case group (105 case) which included accessible breast cancer patients, all of them received the health services in oncology daily-care clinics in the two main hospitals in Gaza strip "Al Shifa and European Gaza hospitals" from January to September 2015.The second type of the tested study population was control group (209 case) free from breast cancer as they were selected from women utilizing the primary health care centers.
\end{abstract}

Results: There is a difference between two groups in terms of age group of both cases and controls. The difference between the two groups reach a statistical significant level $(\mathrm{P}=0.001)$, otherwise no other socio-demographic data reached a statistical significant level. Therefore, more aged women had higher breast cancer $79 \%(\mathrm{n}=83)$ more than 40 years old. Breast cancer incidence is very low in age group between 18-25 years about $1.9 \%$, moderate incidence in age group between 26-40 years about $19 \%$.

Conclusion: age is considered as one of the risk factors that affect the chance of getting breast cancer among women. Also, classified as one of the risk factors that affect breast cancer disease among women. Breast cancer incidence is very low in age group between 18-25.

Keywords: Age; Breast Cancer;Risk Factors

\section{Introduction}

Cancer continuous to be a world killer and it account the one of third disease threaten health in the world. According to World Health Organization (WHO); globally during 2012 about 8.2 million people died from cancer. More than $70 \%$ of those deaths occurred in low and middle income countries. About $30 \%$ of cancer deaths are due to the five-leading behavioral and dietary risks: high Body Mass Index (BMS), low fruit and vegetable intake, lack of physical activity tobacco use and alcohol abuse. Therefore, it could be preserved by modifying or avoiding these risk factors (WHO, 2014)a [1].

Breast cancer is a critical disease in the global burden of disease; it is the most common cancer in women both in the developed and less developed world. According to World Health Organization (WHO) global health estimates (2013), it is estimated that worldwide over 508000 women died in 2011 due to breast cancer. Although breast cancer is thought to be a disease of the developed world, almost $50 \%$ of breast cancer cases and $58 \%$ of deaths occur in less developed countries (WHO, 2014) [1]. Breast cancer is the most prevalent cancer in females worldwide and still the most 
common cause of death in women, with more than 327,000 deaths each year, every year there are 1.35 million new cases and about 4.4 million women are believed to be living with breast cancer, an estimated 1.7 million women will be diagnosed with breast cancer in 2020-a 26\% increase from current levels-mostly in the developing world (The Lancet, 2009). The reported incidence rate for breast cancer varies enormously between countries, it was highest in USA, Europe, New Zealand, Canada and Australia, and lowest in Asia and Africa (IARC, 2002) [2].

Breast cancer remains one of the most common cancers in the Eastern Mediterranean region like the whole world, with incidence rate not higher than the developed world, however it affects women in younger ages and is detected at a late stage. Breast cancer still impacts the developing low and middle income countries more than the high-income countries (Sarhan, 2009) [3]. Now breast cancer occupies the number one position in all countries of the Arab World, even if absolute rates are relatively low (Salim et al., 2009) [4]. Cases tend to be young and almost half of patients are below 50, with a median age of 49-52 years as compared to 63 in industrialized nation (Elsughier et al., 2007) [5].

In Gaza Strip, breast cancer is considered a major public health problem. As expected, it is the first common cancer concerning females and the second leading cause of female death after cardiovascular disease. It accounts more than $18.5 \%$ of all female cancers. The total number of reported breast cancer was 1283 cases during the years 2009-2014, from them 1207 female cases forming $31.3 \%$ of the total cancer cases and 76 male cases forming $1.1 \%$ of the total cancer cases. The incidence rate among Gaza women is 149.1 per 100000 women in the period 2009-2014. In addition, the age group 55-64 reported the maximum number of cases 317 forming $24.7 \%$ of the total cases; this rate is one third of the rate reported among the American women (WHO, 2016).

\section{Methodology}

\section{Study Design}

The study designed to be a hospital based case-control study, it was an observational analytical retrospective investigation, and it is very useful to investigate the possible risk factors of breast cancer among women in Gaza Strip.

\section{Study Population}

The study population consisted of two types; case group which included accessible breast cancer patients. The total number of available cases was 105 subjects. Double controls were chosen as another type of the tested study population, they were selected from women utilizing the primary health care centers. Total number of controls was 209 subjects; this group of subjects is considered free from breast cancer.

\section{Selection Criteria}

\section{Cases}

Cases were diagnosed as breast cancer patient. They must be registered in the oncology services archive and their medical services are available in the two selected hospitals. Diagnosis of the disease was confirmed by histological testing and documented by histological report which should be provided in their files.

\section{Controls}

Controls are clinically free from breast cancer as they were chosen from primary heath care centers, thus they may have minor health problems. Must not suffer from idiopathic weight loss and no history of chronic health problems.

\section{Place of the Study}

The first part the study was to collect cases; it was performed at the oncology daycare clinics of both Al Shifa and European Gaza Hospitals, which are considered the main governmental hospitals providing the oncology services to the cancer patients in Gaza strip. Whereas the second part was to collect control, it was established through the primary health care centers of the same governorates to apply the matching process in the place residency.

\section{Data Collection}

Data were collected through structured face to face questionnaire. It had been reviewed by 7 experts who are qualified in many fields related to the study. Generally, the questionnaire was included many variables that are directly and indirectly reflects the outcomes needed for the study. Before the beginning of data collection, all questionnaire form prepared, organized and classified with serial numbers to ensure the availability of the needed information. Purpose of the study was explained to the patients before obtaining consent, during the interview any vague information was simplified to ensure exact and real answer by the responders. Great care was taken to ensure privacy and confidentiality.

\section{Pilot Study}

Pilot testing had been done prior to the beginning of data collection to check validity of the Questionnaire, refining of questionnaire had been done according to the result of the pilot study.

\section{Period of the Study}

The study carried out from January to September 2015.

\section{Response Rate}

The study response rate was of high levels. From the 1228 , available cases that were going with the inclusion criteria and being asked to participate in the study 105 patients agreed to be a member of the conducted study giving a response rate of $77 \%$. 
Controls response rate was even higher to reach $66 \%$ that from 140 persons who match with the controls criteria 657 members agree to share in the study.

\section{Ethical Considerations}

An informed consent attached to each questionnaire obtained from each participant in the Study. The researcher explained the purpose and the objectives of the study to all the participants, and the inclusion in the study was optional and confidential. Neither name nor personal data had been published.

\section{Statistical Analysis}

Statistical Package for Social Sciences version 15 (SPSS,
2007) used for data coding, entry and analysis. Simple distribution and frequencies of the study variables, the cross tabulation, and normal chi square had been applied. $\mathrm{P}$ value had been calculated for the ordinal level measures $(\mathrm{P}<0.05)$, variables that are statistically significant by chi square test had been analyzed using odds ratio and $95 \%$ confidence interval.

\section{Results and Discussion}

The results of the study show the descriptive and inferential analysis of the findings. In general, 314 questionnaires had been filled from the interviewees during face to face interview with the participants, of which 105 were case samples (women with breast cancer) and 209 were control sample (women free from breast cancer).

\begin{tabular}{|c|c|c|c|c|c|c|c|c|c|}
\hline \multirow{2}{*}{ Governorate } & \multicolumn{3}{|c|}{ Case } & \multicolumn{2}{c|}{ Control } & \multicolumn{2}{c|}{ Total } & P-value & CI \\
\cline { 2 - 10 } & No. & $\%$ & No. & $\%$ & No. & $\%$ & & \\
\hline North Gaza & 17 & 16.2 & 32 & 15.3 & 49 & 15.6 & & \\
\hline Gaza & 48 & 45.7 & 97 & 46.4 & 145 & 46.2 & & \\
\hline Mid-Zone & 16 & 15.2 & 31 & 14.8 & 47 & 15 & 0.996 & - & - \\
\hline South Gaza & 24 & 22.9 & 49 & 23.4 & 73 & 23.2 & & \\
\hline Total & 105 & 100 & 209 & 100 & 105 & 100 & & \\
\hline
\end{tabular}

Table 1: Breast Cancer and Governorate Name.

(Table 1) presents the relationship between socio-demographic variables and breast cancer among cases and controls. Regarding Governorates where cases and controls have been lived, the difference between the two groups did not reach a statistical significant level $(\mathrm{P}=0.996)$. This means that the Governorate does not affect the chance of gettingbreast cancer because the two groups have been matched in regard to governorates

\begin{tabular}{|c|c|c|c|c|c|c|c|c|c|}
\hline \multirow{2}{*}{ Living area } & \multicolumn{2}{|c|}{ Case } & \multicolumn{2}{|c|}{ Control } & \multicolumn{2}{|c|}{ Total } & \multirow[t]{2}{*}{ P-value } & \multirow[t]{2}{*}{ CI } & \multirow[t]{2}{*}{ Odds ratic } \\
\hline & No. & $\%$ & No. & $\%$ & No. & $\%$ & & & \\
\hline Agricultural & 22 & 21 & 42 & 20.1 & 64 & 20.4 & & & \\
\hline Industrial & 24 & 22.9 & 44 & 21.1 & 68 & 21.7 & & & \\
\hline Border & 16 & 15.2 & 46 & 22 & 62 & 19.7 & 0.56 & - & - \\
\hline Residential towers & 43 & 41 & 77 & 36.8 & 120 & 38.2 & & & \\
\hline Total & 105 & 100 & 209 & 100 & 314 & 100 & & & \\
\hline
\end{tabular}

Table 2: Breast Cancer and Living Area Characteristics.

(Table 2) presents the relationship between kinds of living area and its relationship with breast cancer, difference between the two groups did not reach a statistical significant level also $(\mathrm{P}=0.556)$. This means that neither governorate nor kind of living area in this study affects the chance ofgetting breast cancer because the two groups have been matched in regard to the living area. These results are congruent with Pakseresht case-control study (2009) [6] conducted in Delhi and showed that there was a significant difference between breast cancer cases and controls in relation to the marital status. However, these results do not congruent with another study that has been conducted in West Bank by Darweesh (2009) [7] who found that there was no association between marital status and breast cancer. 
Citation: Khadoura KJ (2017) Socio-Demographic Risk Factors Associated with Breast Cancer in Gaza Strip. J NursWomens Health: JNWH-118.

\begin{tabular}{|c|c|c|c|c|c|c|c|c|c|}
\hline \multirow{2}{*}{ Age group } & \multicolumn{2}{|c|}{ Case } & \multicolumn{2}{|c|}{ Control } & \multicolumn{2}{|c|}{ Total } & \multirow[t]{2}{*}{ P-value } & \multirow[t]{2}{*}{ CI } & \multirow[t]{2}{*}{ Odds ratio } \\
\hline & No. & $\%$ & No. & $\%$ & No. & $\%$ & & & \\
\hline $18-25$ years & 2 & 1.9 & 26 & 12.4 & 28 & 8.9 & & & \\
\hline $26-40$ years & 20 & 19 & 57 & 27.3 & 77 & 24.5 & 0.001 & - & - \\
\hline $\begin{array}{c}\text { More than } \\
40 \text { years }\end{array}$ & 83 & 79 & 126 & 60.3 & 209 & 66.6 & & & \\
\hline Total & 105 & 100 & 209 & 100 & 314 & 100 & & & \\
\hline
\end{tabular}

Table 3: Breast Cancer and Age Group.

As indicated in (Table 3), there is a difference between two groups in terms of age group of both cases and controls and more age women had higher breastcancer. The differencebetween the two groups reach a statistical significant level $(\mathrm{P}=0.001)$. Therefore, age is considered as one of the risk factors that affect the chance of getting breastcancer among women and classified as one of the risk factors that affect breast cancer disease among women. It was reported that breast cancer incidence is very low before age 25, and increases up to 100 -fold by age 45 (Hulka and Moorman, 2001) [8].

\begin{tabular}{|c|c|c|c|c|c|c|c|c|c|}
\hline \multirow{2}{*}{$\begin{array}{c}\text { Marital } \\
\text { status }\end{array}$} & \multicolumn{2}{|c|}{ Case } & \multicolumn{2}{|c|}{ Control } & \multicolumn{2}{|c|}{ Total } & \multirow[t]{2}{*}{ P-value } & \multirow[t]{2}{*}{ CI } & \multirow[t]{2}{*}{ Odds ratio } \\
\hline & No. & $\%$ & No. & $\%$ & No. & $\%$ & & & \\
\hline Single & 8 & 7.6 & 11 & 5.3 & 19 & 6.1 & & & \\
\hline Married & 81 & 77.1 & 160 & 76.6 & 241 & 76.8 & & & \\
\hline Divorced & 3 & 2.9 & 13 & 6.2 & 16 & 5.1 & 0.531 & - & - \\
\hline Widowed & 13 & 12.4 & 25 & 12 & 38 & 12.1 & & & \\
\hline Total & 105 & 100 & 209 & 100 & 314 & 100 & & & \\
\hline
\end{tabular}

Table 4: Breast Cancer and Marital Status.

(Table 4) presents the marital status and its relationship with breast cancer, the difference between the two groups did not reach a statistical significant level also $(\mathrm{P}=0.531)$. This means that the material status does not affect the chance of getting breast cancer because the two groups have been matched in regard to material status. These results are agreeing with Pakseresht case-control study (2009) [6] conducted in Delhi and showed that there was a significant difference between breast cancer cases and controls in relation to the marital status. However, these results congruent with another study that has been conducted in West Bank by Darweesh (2009) [7] who found that there was no association between marital status and breast cancer.

\begin{tabular}{|c|c|c|c|c|c|c|c|c|c|}
\hline \multirow{2}{*}{$\begin{array}{l}\text { Number of } \\
\text { Children }\end{array}$} & \multicolumn{2}{|c|}{ Case } & \multicolumn{2}{|c|}{ Control } & \multicolumn{2}{|c|}{ Total } & \multirow[t]{2}{*}{ P-value } & \multirow[t]{2}{*}{ CI } & \multirow[t]{2}{*}{ Odds ratio } \\
\hline & No. & $\%$ & No. & $\%$ & No. & $\%$ & & & \\
\hline Less than 3 & 6 & 5.7 & 39 & 18.7 & 45 & 14.3 & & & \\
\hline 5-Mar & 24 & 22.9 & 53 & 25.4 & 77 & 24.5 & & & \\
\hline More than 5 & 56 & 53.3 & 94 & 45 & 150 & 47.8 & 0.007 & - & - \\
\hline Nothing & 19 & 18.1 & 23 & 11 & 42 & 13.4 & & & \\
\hline Total & 105 & 100 & 209 & 100 & 314 & 100 & & & \\
\hline
\end{tabular}

Table 5: Breast Cancer and Number of Children.

(Table 5) represents the relationship between breast cancer and number of children indicates the difference between the two groups did not reach a statistical significant level $(\mathrm{P}=0.007)$. This means that number of children have no effects on the chance of getting breast cancer so it has no association with breast cancer among women in Gaza Governorate. 
Citation: Khadoura KJ (2017) Socio-Demographic Risk Factors Associated with Breast Cancer in Gaza Strip. J NursWomens Health: JNWH-118.

\begin{tabular}{|c|c|c|c|c|c|c|c|c|c|}
\hline \multirow{2}{*}{ The Work } & \multicolumn{2}{|c|}{ Case } & \multicolumn{2}{|c|}{ Control } & \multicolumn{2}{|c|}{ Total } & \multirow[t]{2}{*}{$\mathrm{P}$-value } & \multirow[t]{2}{*}{$\mathrm{CI}$} & \multirow[t]{2}{*}{ Odds ratio } \\
\hline & No. & $\%$ & No. & $\%$ & No. & $\%$ & & & \\
\hline Employed & 11.1 & 35 & 10.5 & 22 & 12.4 & 13 & & & \\
\hline $\begin{array}{l}\text { Unem- } \\
\text { ployed }\end{array}$ & 88.9 & 279 & 89.5 & 187 & 87.6 & 92 & 0.622 & $2.492-0.579$ & 1.201 \\
\hline Total & 100 & 314 & 100 & 209 & 100 & 105 & & & \\
\hline
\end{tabular}

Table 6: Breast Cancer and the Work of Woman.

(Table 6) shows that $12.4 \%$ of cases workers women compared to $10.5 \%$ of controls, while $87.6 \%$ of cases did not have a work compared to $89.5 \%$ of controls. The difference between two groups did not reach a statistical significant level $(\mathrm{P}=0.622, \mathrm{OR} 0.201)$. This factor does not affect the chance of getting breast cancer so it does not consider as a risk factor of breast cancer.

\begin{tabular}{|c|c|c|c|c|c|c|c|c|c|}
\hline \multirow{2}{*}{$\begin{array}{c}\text { Educational } \\
\text { Level }\end{array}$} & \multicolumn{2}{|c|}{ Case } & \multicolumn{2}{|c|}{ Control } & \multicolumn{2}{|c|}{ Total } & \multirow[t]{2}{*}{ P-value } & \multirow[t]{2}{*}{ CI } & \multirow[t]{2}{*}{ Odds ratio } \\
\hline & No. & $\%$ & No. & $\%$ & No. & $\%$ & & & \\
\hline Elementary & 19 & 18.1 & 23 & 11 & 42 & 13.4 & & & \\
\hline preparatory & 25 & 23.8 & 58 & 27.8 & 83 & 26.4 & & & \\
\hline Secondary & 39 & 37.1 & 82 & 39.2 & 121 & 38.5 & 0.369 & - & - \\
\hline Bachelor & 22 & 21 & 46 & 22 & 68 & 21.7 & & & \\
\hline Total & 105 & 100 & 209 & 100 & 314 & 100 & & & \\
\hline
\end{tabular}

Table 7: Breast Cancer and Educational Level.

As indicated in (Table 7), there is a no difference between two groups in terms of educational level of both cases and controls the difference between the two groups doesn't reach a statistical significant level $(\mathrm{P}=0.369)$. Therefore, education does not consider as one of the risk factors that affect the chance of getting breast cancer among women.

\begin{tabular}{|c|c|c|c|c|c|c|c|c|c|}
\hline \multirow{2}{*}{$\begin{array}{l}\text { Type of } \\
\text { House }\end{array}$} & \multicolumn{2}{|c|}{ Case } & \multicolumn{2}{|c|}{ Control } & \multicolumn{2}{|c|}{ Total } & \multirow[t]{2}{*}{ P-value } & \multirow[t]{2}{*}{$\mathrm{CI}$} & \multirow[t]{2}{*}{ Odds ratio } \\
\hline & No. & $\%$ & No. & $\%$ & No. & $\%$ & & & \\
\hline villa & 1 & 1 & 2 & 1 & 3 & 1 & & & \\
\hline $\begin{array}{c}\text { An apart- } \\
\text { ment }\end{array}$ & 49 & 46.7 & 78 & 37.3 & 127 & 40.4 & & & \\
\hline Independent & 48 & 45.7 & 87 & 41.6 & 135 & 43 & 0.02 & - & - \\
\hline Asbestos & 7 & 6.7 & 42 & 20.1 & 49 & 15.6 & & & \\
\hline Total & 105 & 100 & 209 & 100 & 314 & 100 & & & \\
\hline
\end{tabular}

Table 8: Breast Cancer and Type of House.

\begin{tabular}{|c|c|c|c|c|c|c|c|c|c|}
\hline \multirow{2}{*}{$\begin{array}{l}\text { Urban and } \\
\text { Rural living } \\
\text { site }\end{array}$} & \multicolumn{2}{|c|}{ Case } & \multicolumn{2}{|c|}{ Control } & \multicolumn{2}{|c|}{ Total } & \multirow[t]{2}{*}{ P-value } & \multirow[t]{2}{*}{ CI } & \multirow[t]{2}{*}{ Odds ratio } \\
\hline & No. & $\%$ & No. & $\%$ & No. & $\%$ & & & \\
\hline City & 71 & 67.6 & 136 & 65.1 & 207 & 65.9 & & & \\
\hline Village & 7 & 6.7 & 14 & 6.7 & 21 & 6.7 & 0.891 & - & - \\
\hline Camp & 27 & 25.7 & 59 & 28.2 & 86 & 27.4 & & & \\
\hline Total & 105 & 100 & 209 & 100 & 105 & 100 & & & \\
\hline
\end{tabular}

Table 9: Breast Cancer and Living Site Characteristics.

(Table 8 and Table 9) illustrate the difference between the two groups in housing type and place of living also doesn't reach a statistical significant level $(\mathrm{P}=0.020$ and 0.891$)$ respectively, indicating that housing type and place of living doesn't affects the chance of getting breast cancer disease. 


\section{Conclusion}

There is a difference between two groups in terms of age group of both cases and controls. The difference between the two groups reach a statistical significant level $(\mathrm{P}=0.001)$, otherwise no other socio-demographic data reached a statistical significant level. Therefore, more aged women had higher breast cancer $79 \%$ ( $n=$ 83 ) more than 40 years old. Breast cancer incidence is very low in age group between $18-25$ years about $1.9 \%$, moderate incidence in age group between $26-40$ years about $19 \%$. Age is considered as one of the risk factors that affect the chance of getting breast cancer among women. Also, classified as one of the risk factors that affect breast cancer disease among women.

\section{References}

1. World Health Organization (2014) Breast cancer: prevention and control.

2. IARC Working Group on the Evaluation of Carcinogenic Risks to Humans, World Health Organization, and International Agency for Research on Cancer (2002)Non-ionizing Radiation: Static and Extremely Low-Frequency (ELF) electric and magnetic fields. No. 80. World Health Organization.'

3. Sarhan AM (2009) Cancer classification based on microarray gene expression data using DCT and ANN. Journal of theoretical and applied information technology 6: 208-216.
4. Salim El, Moore MA, Al- Lawati JA, Al-Sayyad JA, Bazawir A, et al. (2009) Cancer epidemiology and control in the arab world-past, present and future. Asian Pac J Cancer Prev 10: 3-16.1

5. Elsaghir NS, Khalil MK, Eid T, Elkinge AR, Charafeddine M, et al. (2007) Trends in epidemiology and management of breast cancer in developing Arab countries: a literature and registry analysis. Int J Surg $5: 225-233$

6. Pakseresht S, Ingle GK, Bahadur AK, Ramteke VK, Singh MM, et al. (2009)Risk factors with breast cancer among women in Delhi. Indian journal of cancer 46: 132-138.

7. DarweeshAlaa (2009) Risk factors of breast cancer among Palestinian women in North West Bank. Diss. Faculty of Graduate Studies Risk Factors of Breast Cancer among Palestinian Women in North West Bank byAlaaDarweesh Supervisor Dr. Ayman Hussein This Thesis is submitted in partial fulfillment of the requirements for the degree of Master in Public Health, Faculty of Graduate Studies, An-Najah National University: 1-77.

8. Hulka BS, Moorman PG (2001) Breast cancer: hormones and other risk factors. Maturitas 38: 103-116.

9. World Health Organization (2014) Women's health. Media center, Fact sheet $\mathrm{N}^{\circ} 334$.

10. Beraval V (2003) Breast Cancer and Hormone-Replacement Therapy in the Million Women Study. The Lancet 362: 419-427. 